\title{
Effect of TRX Suspension Training on Abdominal Strength and Isometric Muscle Endurance of Police College Students
}

\author{
Fan Zhang \\ Department of Police Skills and Tactics \\ Nanjing Forest Police College \\ No. 28 Wen Lan Road, Qixia District \\ Nanjing, JIANGSU 210023 China \\ zhangfan@nfpc.edu.cn
}

\begin{abstract}
This study discussed the effects of 12-week TRX suspension training and instrument resistance training on abdominal muscle strength and isometric abdominal muscle endurance of police college students. Thirty male students from Nanjing Forest Police College were randomly divided into TRX suspension training group and instrument resistance training group. Each group received a 90-minute training course twice a week for 12 weeks. The abdominal muscle strength and abdominal muscle tolerance were measured before and after training. After statistical analysis of $T$ test of dependent samples, it was found that TRX suspension training group had significant improvement in abdominal muscle strength and other longissimus muscle strength, while instrument resistance training group had significant improvement only in abdominal muscle strength. Therefore, the choice of TRX suspension training, compared with the device resistance training, can significantly enhance the core muscle capacity.
\end{abstract}

Keywords-Police college; TRX; Abdominal strength; Isometric muscle endurance

\section{INTRODUCTION}

The quality of policeman's physical ability is not only the guarantee of police force, but also the cornerstone of police security enforcement. In view of the latest concept of physical training (such as TRX training and core muscle strengthening) and the actual impact of police enforcement, the development of core muscle and explosive force has gradually become the core index to measure the professional physical ability of the police. As a traditional physical training model often used by probationary police officers (police college students), the apparatus resistance training with equipment is a systematic and planned method which aims to improve physical ability and athletic ability to raise training performance. However, the contradiction is that there is an increase in sports injury probability and a decrease in training benefits. In order to verify the difference between TRX training and traditional apparatus resistance training in physical quality, this study takes TRX training and apparatus resistance training as variables to observe the influence and difference of the two training methods on the abdominal muscle strength and isometric muscle endurance of police college students, with a view to providing scientific reference for the reform of teaching content of police physical ability courses in public security colleges.

\section{RESEARCH OBJECTS AND METHODS}

\section{A. Research Objects}

Thirty male college students from Nanjing Forest Police College were subjects, with an average age of $19.4 \pm 1.3$ yrs., an average height of $173.5 \pm 3.4 \mathrm{~cm}$ and an average weight of $68.7 \pm 3.9 \mathrm{~kg}$. They were randomly divided into the experimental group of 15 and the control group of 15 . The experimental group was given TRX suspension training, while the control group was given apparatus resistance training.

\section{B. Research Methods}

\section{1) Experimental Control:}

a) It is confirmed that all subjects have no cardiovascular diseases, hypertension and related visceral diseases, and can accept the maximum exercise test;

b) Subjects are not allowed to take part in any strenuous exercise or drink drinks containing caffeine, creatine, branched-chain amino acids and alcohol within 24 hours before the experiment and are required to sleep for at least 6 hours;

c) The subjects should not have any history of upper limb muscle and joint injuries in the past six months in order to avoid experimental deviation;

d) The subjects are not allowed to be engaged in strenuous exercise and produce muscle injury or soreness before the measurement on the week and day of the experiment;

e) Each measurement time is controlled in the same time period to avoid interfering variables;

f) The average height and weight of the subjects are controlled within 5 to avoid experimental errors caused by additional factors;

g) On the day of the experiment, all the subjects do not have any ongoing diseases, such as cold, fever, etc. 
h) It is ensured that the subjects understand the purpose, process and rights of this experiment and complete the experiment indoors.

\section{2) Experimental Design:}

\section{a) Experimental Process}

According to the purpose of this study, all subjects were randomly divided into TRX suspension training ( TRX ) and apparatus apparatus resistance training ( ART ) for 12 weeks, twice a week for 90 minutes. The experimental process is divided into three stages:

- Pret-test of abdominal muscle strength, abdominal muscle isometric endurance.

- 12-week TRX suspension training and apparatus resistance training.

- Post-test of abdominal muscle strength, abdominal muscle strength.

\section{b) Training Course}

Training course divides the 90-minute course into 3 parts:

- Warm-up exercise. It lasts 15 minutes. It takes lowintensity aerobic exercise to raise the body's working temperature, improve muscle elasticity and extensibility through dynamic stretching, increase the range of joint movement and connecting sensory and motor neurons as the main training courses and avoid sports injuries $[1,2]$.

- Main courses ( TRX suspension training and equipment apparatus resistance training). It lasts 60 minutes. In this study, 10 muscle parts of the large muscle group of the body are used as the main training parts for TRX suspension training and equipment apparatus resistance training, including rectus abdominis, erector spinae, internal and external oblique muscles. Table 1 shows the principles of TRX suspension training and apparatus resistance training.

- Relaxation exercise. It lasts 15 minutes. It takes the initiative to recover with low-intensity aerobic or stretching movements, accelerate the discharge of metabolic wastes in the body after training, relieve the tight muscle parts after training, reduce the accumulation of lactic acid and stretch the muscles of each training part, and reduce the muscle soreness and fatigue after exercise.

TABLE I. PRINCIPLES OF TRAINING

\begin{tabular}{|c|c|c|}
\hline \multirow[b]{2}{*}{ Parameter } & \multicolumn{2}{|c|}{ Training type } \\
\hline & TRX Suspension Training & Resistance Training \\
\hline Preset & \multicolumn{2}{|c|}{$\begin{array}{l}\text { Before the start of the course, the subjects are arranged to experience the course description and actual operation, and } \\
\text { measure the maximum muscle strength ( } 1 \mathrm{RM}) \text { so that the } 12 \text { - week training can proceed smoothly. }\end{array}$} \\
\hline Times of Repetition & \multicolumn{2}{|c|}{$\begin{array}{l}\text { According to the suggestion of ACSM ( } 2011 \text { ) of the American Sports Medical Association, the recommended number } \\
\text { of repetitions for improving muscle fitness is } 8-12 \text { times. Therefore, this study adopts ACSM's suggestion and sets the } \\
\text { times of repetitions for each group to } 8-12 \text { times. }\end{array}$} \\
\hline Repeated Group & \multicolumn{2}{|c|}{$\begin{array}{l}\text { In the first } 6 \text { weeks, the number of repeated groups for each muscle part was } 2 \text { groups, and in the last } 6 \text { weeks, the } \\
\text { muscle fitness of TRX suspension training group and equipment resistance training group was increased to } 3 \text { groups. }\end{array}$} \\
\hline Load & $\begin{array}{l}\text { Adjust the load intensity by angle, based on the } \\
\text { number of repetitions of } 8 \sim 12 \text {. }\end{array}$ & $\begin{array}{l}\text { Based on the maximum muscle strength ( } 1 \mathrm{RM}) \text { of } 70 \% \sim 80 \% \text {, } \\
\text { the number of repetitions should be } 8 \sim 12 .\end{array}$ \\
\hline \multicolumn{3}{|l|}{$\begin{array}{l}\text { 3) Training Method: } \\
\text { a) Rectus Abdomin }\end{array}$} \\
\hline
\end{tabular}
the load, lie on your back and point your foot toward the anchor point ( TRX sling), with spine flexion and contraction of rectus abdominis as the main actions, the farther away your body from the anchor point, the lighter the load. The body lies
ART group: With spine flexion and contraction of rectus abdominis as the main movements, the number of bars is adjusted by $8 \sim 12 \mathrm{RM}$ to determine the weight load, as shown in Table 2.

TABLE II. RECTUS ABDOMINIS TRAINING

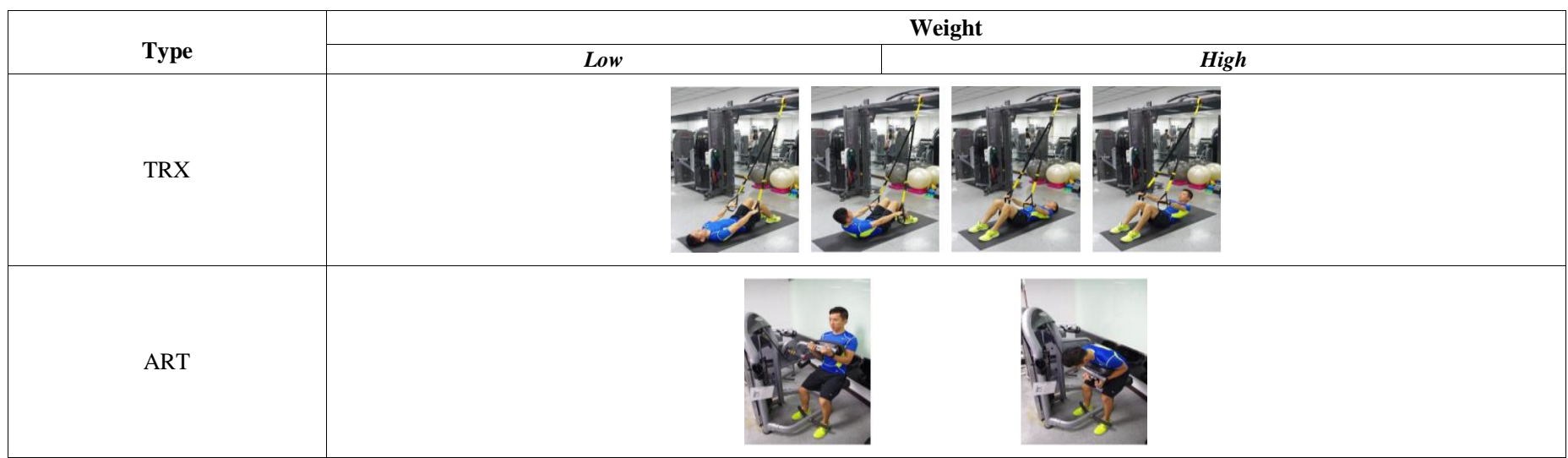




\section{b) Erector Spinae Training}

TRX group: The subjects repeat $8 \sim 12 \mathrm{RM}$ times to adjust the load, with the body prone under the anchor point ( TRX binding position ), with spine stretching and erector spinae contraction as the main movements, with both hands in a capitulation position, with the weight lighter as the body gets closer to the anchor point $[3,4]$. The farther they stretch their body from the anchor point, the heavier their weight will be.

ART group: With spine stretching and erector spinae contraction as the main movements, the weight of hand-held dumbbells is adjusted $8 \sim 12 \mathrm{RM}$ to determine the weight, as shown in Table 3.

TABLE III. ERECTOR SPINAE TRAINING

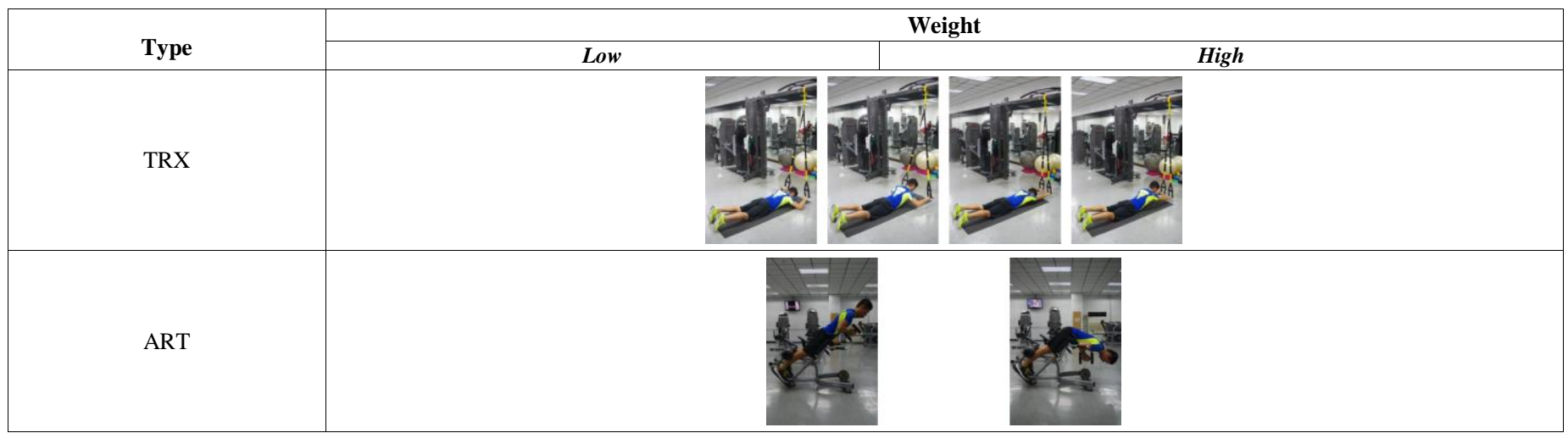

c) Internal and External Oblique Muscle Training

TRX group: The subjects repeat $8 \sim 12 \mathrm{RM}$ times to adjust the load, with the body facing the anchor point ( TRX binding position ), with the contraction of the left and right rotation of the spine, internal and external oblique muscles as the main action, using the body weight as the load, the lighter the weight of the body perpendicular to the floor, the heavier the weight of the body parallel to the floor $[5,6]$.

ART group: the main movements were left and right rotation of the spine, internal and external oblique muscle contraction, and the number of repetitions is $8 \sim 12 \mathrm{RM}$ to adjust the number of bars to determine the weight load, as shown in Table 4.

TABLE IV. INTERNAL AND EXTERNAL OBLIQUE MUSCLE TRAINING

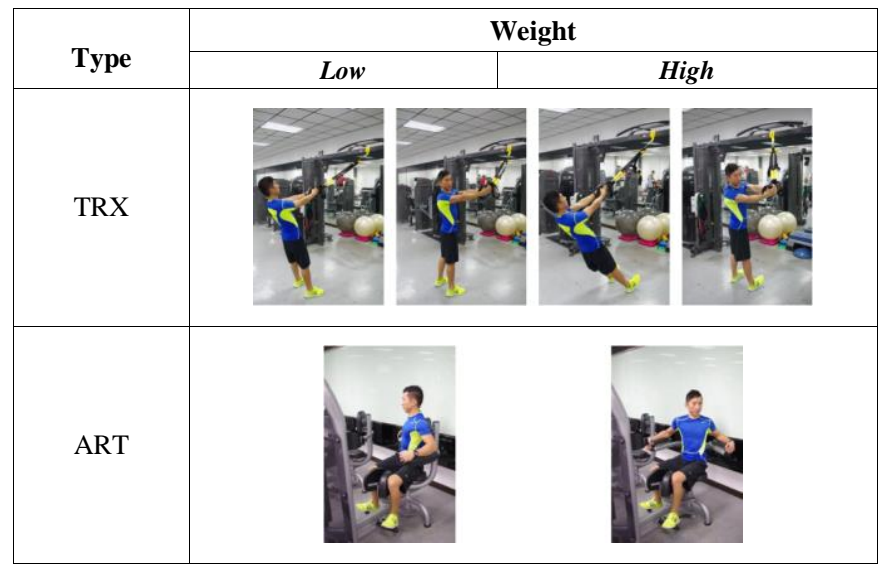

4) Experimental Indicators:

\section{a) Strength of Abdominal Muscle}

Equipment: yoga mats, stopwatches, fixing belts and handheld electronic muscle strength meters.

Steps:
- Subject lies flat on the yoga mat, with the hip joint and knee joint flexed, touching the knee with their fingers and maintaining this position.

- At this time, the researcher placed the hand-held electronic muscle strength measuring instrument about $3 \mathrm{~cm}$ below the sternal notch.

- The subject is given the maximum resistance they can bear to measure the maximum muscle strength of their abdominal muscles until the fingers of the subjects leave their knees, a total of three test

b) Isometric Endurance of Abdominal Muscle

Equipment: yoga mats, stopwatches and fixing belts.

Steps:

- The subject lies flat on the yoga mat, bend the knee joint 90 degrees, and lay the palm of both feet on the bed surface during preparation.

- When hearing the start command, the subject straighten his arm toward his knee and touch his knee with his finger to maintain this position.

- The researchers record the time when the subject can maintain this position with a stopwatch and record it.

\section{5) Statistical Processing and Analysis:}

SPSS 19.0 was used for statistical processing, and the results were expressed by means standard deviation $(\bar{X} \pm \mathrm{SD})$. The basic data of TRX suspension training group and instrument apparatus resistance training group were analyzed by independent sample $\mathrm{T}$ test. The influence of TRX suspension training group and instrument apparatus resistance training group on core muscle group and explosive force was compared by paired sample $\mathrm{T}$ test. Statistically the significant level was $P<0.05$ and the extremely significant level was for $P<0.01$. 


\section{RESULTS AND ANALYSIS}

A. Difference of the effect between TRX Suspension Training and apparatus resistance training on abdominal muscle strength

In the TRX suspension training group, the anterior mean of abdominal muscle strength before exercise intervention was $63.86 \pm 8.21$, and after the exercise intervention, the $77.79 \pm 8.08$ of the abdominal muscle force in the anti-apparatus resistance training group was $65.86 \pm 10.29$ before the exercise intervention, and the posterior test was 75.64 \pm after the exercise intervention. 9.62, with paired samples $\mathrm{T}$ test analysis TRX suspension training group and the apparatus resistance training group after exercise intervention for abdominal muscle strength training difference before and after the results found that the two groups in the exercise after intervention for abdominal muscle strength have significant progress $(\mathrm{P}<0.05)$. Table 5 shows the difference of the effect between TRX Suspension Training and apparatus resistance training on abdominal muscle strength.

TABLE V. COMPARISON OF ABDOMINAL STRENGTH

\begin{tabular}{|c|c|c|c|c|}
\hline Test & group & Pre-test & Post-test & $\boldsymbol{P}$ \\
\hline $\begin{array}{c}\text { abdominal } \\
\text { strength }\end{array}$ & TRX & $63.86 \pm 8.21$ & $77.79 \pm 8.08$ & $0.013^{*}$ \\
\cline { 2 - 5 } & ART & $65.86 \pm 10.29$ & $75.64 \pm 9.62$ & $0.036^{*}$ \\
\hline
\end{tabular}

\section{B. Difference of isometric endurance training effect of TRX}

suspension training and apparatus resistance training for abdominal muscles

For TRX suspension training group of abdominal muscle endurance, before the exercise intervention, the average was 47.23 \pm 22.75 . The result of exercise intervention after the test was $74.50 \pm 28.71$. The average of the apparatus resistance training group of anti-abdominal muscles and other long muscle endurance part before the movement involved in the pre-test average was $48.06 \pm 16.42$, After the exercise intervention, the post-test was $68.99 \pm 19.19$, and the training group of TRX suspension training group and the apparatus resistance training team were different before and after the exercise intervention, and the results showed that the TRX suspension training group had remarkable progress in the endurance of abdominal muscles after the exercise intervention $(\mathrm{P}<0.01)$. The apparatus resistance training Group of the apparatus had not progressed significantly to the endurance of the abdominal muscles after the exercise intervention $(\mathrm{P}>$ $0.05)$. Table 6 shows the difference of the effect between TRX Suspension Training and apparatus resistance training on abdominal muscle strength. difference of isometric endurance training effect of TRX suspension training and apparatus resistance training for abdominal muscles.

TABLE VI. COMPARISON OF ABDOMINAL ISOMETRIC MUSCLE ENDURANCE

\begin{tabular}{|c|c|c|c|c|}
\hline Test & group & Pre-test & Post-test & $\boldsymbol{P}$ \\
\hline $\begin{array}{c}\text { Isometric } \\
\text { muscle } \\
\text { endurance }\end{array}$ & TRX & $47.23 \pm 22.75$ & $74.50 \pm 28.71$ & $0.001 * *$ \\
\cline { 2 - 5 } & ART & $48.06 \pm 16.42$ & $68.99 \pm 19.19$ & 0.092 \\
\hline
\end{tabular}

\section{CONCLUSION}

The training effect of TRX suspension training and apparatus resistance training on the core muscle group of police college students has been significantly improved, and the training effect of TRX suspension training on the core muscle group of the police college students is better than the apparatus resistance training of the apparatus. The training effect of TRX suspension training on the muscle endurance of the core muscle group of the police college students has been significantly improved, and the apparatus resistance training of the apparatus has no significant progress on the muscular endurance of the core muscle group of the police college students. In the future, for different grades and different sex, we should do comparative research, because the load of TRX suspension training is from their own weight and gravity; muscle fitness may not achieve a good training effect. Compared with the instrument-type apparatus resistance training that can adjust load weight with no limitation, some students may not be the best practical effect. Some studies have pointed out that unstable surface training has a substantial benefit in increasing the training effect of core muscle group, and it is also in accord with the results of this study. The recent rise of the Swiss ball training and TRX suspension training are all part of the unstable surface training. Future study can be aimed at the nuclear myocardial Group training effect, dynamic and static balance ability, the core stability of the impact of comparison, to explore physical training innovation model of diversification development.

\section{ACKNOWLEDGMENT}

This work was supported in part by the 13th Five-Year plan project of Jiangsu Education Science under Grant Cc/2018/01/11, in part by Jiangsu University Philosophy and Social Sciences Research Fund Project under Grant 2017SJB0590, in part by Nanjing Forest police College Teaching Reform Project under Grant ZD18104, in part by Jiangsu Qing Lan Project under Grant 2017, and in part by Preresearch project of Nanjing Forest police College under Grant LGY201603.

\section{REFERENCES}

[1] Byrne, J. M., et al., "Effect of using a suspension training system on muscle activation during the performance of a front plank exercise," Journal of Strength \& Conditioning Research, vol. 28, pp. 3049-3050, November 2014.

[2] Angus. G, Tobias. M, “TRX Suspension Training: A New Functional Training Approach for Older Adults - Development, Training Control and Feasibility," International Journal of Exercise Science, vol. 8, pp. 224-233, March 2015.

[3] Atkins. S. J, Bentley. I, Brooks. D, et al., "Electromyographic response of global abdominal stabilizers in response to stable- and unstable-base isometric exercise," Journal of Strength \& Conditioning Research, vol. 29, pp. 1609-1613, June 2015.

[4] Cugliari. G, Boccia. G, "Core Muscle Activation in Suspension Training Exercises,” Journal of Human Kinetics, vol. 56, pp. 61-71, March 2017.

[5] Borreani. S, Calatayud. J, Colado. J. C, et al., "Muscle activation during push-ups performed under stable and unstable conditions," Journal of Exercise Science \& Fitness, vol. 13, pp.94-98, February 2015.

[6] Mok. N. W, Yeung. E. W, Cho. J. C, et al., "Core muscle activity during suspension exercises," Journal of Science \& Medicine in Sport, vol. 18, pp. 189-194, March 2015. 